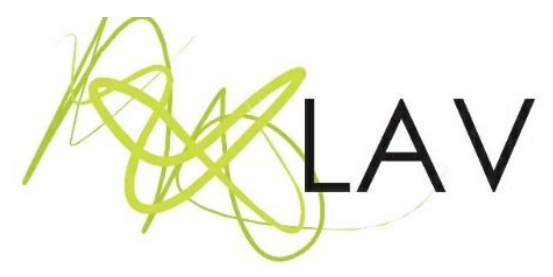

\title{
Arquiteturas do Brincar: cabanas encantadas
}

Architectures of Playing: enchanted huts

Fernanda Ferreira de Oliveira ${ }^{i}$ Universidade Metodista de Piracicaba

Peterson Rigato da Silvaii Universidade Estadual Paulista - Rio Claro

\section{Resumo}

As crianças pequenas criam e inventam possibilidades de existências nos espaços públicos da educação infantil. O presente artigo apresenta as possibilidades de uma pedagogia dos sentidos, em que o processo de criação com as cabanas produzidas e espalhadas pelos espaços evidencia a autoria das crianças e da professora. Apresentando caminhos e transformando os espaços-tempos em uma dinâmica que inquieta e dinamiza os trajetos com abertura para o novo. O diálogo com a arquitetura, a arte e a educação infantil possibilita compreendermos a relevância da existência de um planejamento potente e de um currículo que tendem a ser revistos, pois os campos políticos, estéticos e éticos transitam como uma via de mão dupla, evidenciando o protagonismo e autoria da inventividade e do coletivo infantil.

Palavras-chave: educação infantil, arte, estética.

\begin{abstract}
Young children create and invent possibilities of existence in the public spaces of early childhood education. The present article presents the possibilities of a pedagogy of the senses in which the process of creation with the huts produced and spread throughout the spaces evidences the authorship of the children and the teacher. Presenting paths and transforming space-time in a dynamic that makes the paths restless and dynamic, with openness to the new. The dialogue with architecture, art and child education, allows understanding the relevance of the existence of a powerful planning and a curriculum that tend to be reviewed, because the political, aesthetic and ethical fields transit as a two-way street, highlighting the protagonism and authorship of inventiveness and the children's collective.
\end{abstract}

Keywords: early childhood education, art, aesthetics. 


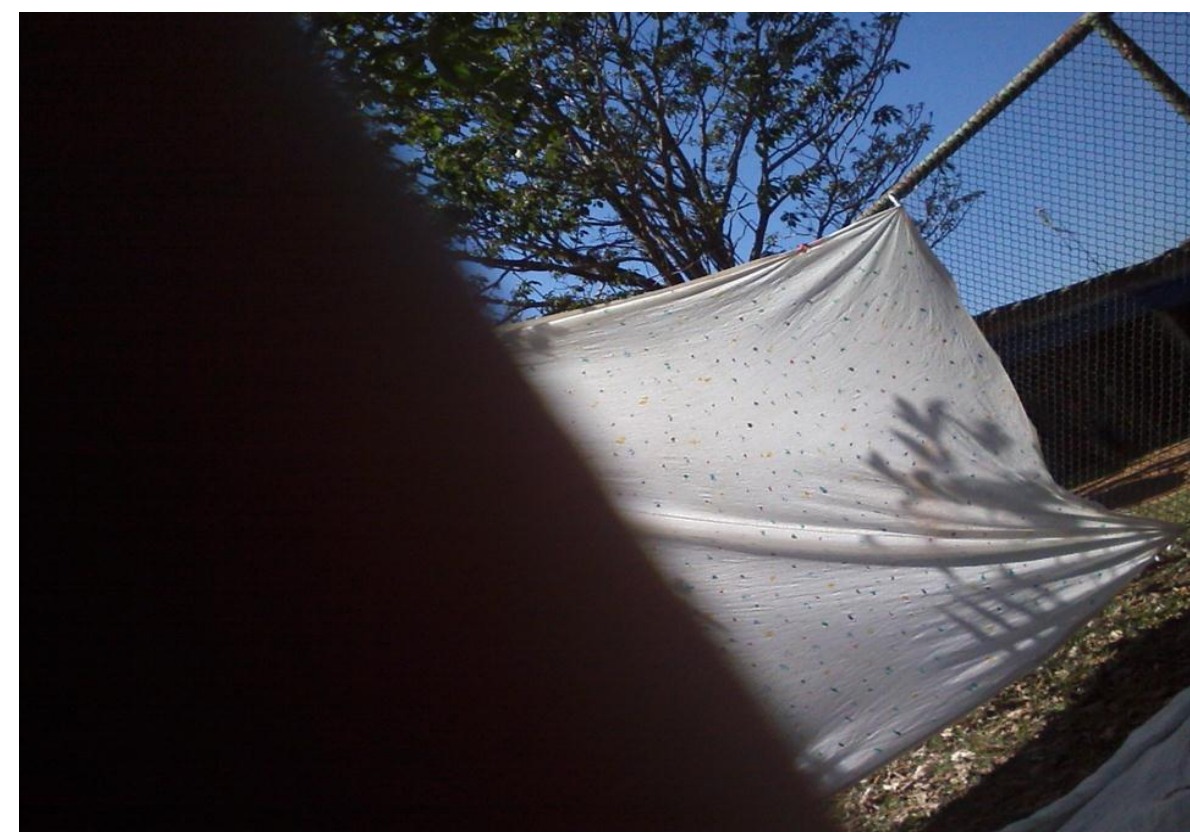

Figura 1: Começo.

Fonte: Arquivo da Professora (2017).

\section{Introdução}

Organizar, pensar e propor experiências estéticas às crianças pequenas da educação infantil constitui uma postura propositiva e intencional docente, e também uma atitude revolucionária diante do cenário contemporâneo, em que a experiência não é valorizada ou opera de maneira pobre, como menciona Walter Benjamin (1985).

Olhares, devaneios, sombras. Um 'corte' diante de olhares. As crianças produzem este efeito e nos tiram do lugar. Abrir este artigo com uma imagem-epígrafe (figura 1) nos desloca do lugar, bem como leva o leitor para outro plano, como um convite a entrar nas cabanas produzidas pelo coletivo infantil. No contexto da creche e da pré-escola temos 'saboreado' situações cotidianas encantadoras com as crianças pequenas e os bebês, que possibilitam compreender como os saberes e sentidos estéticos configuram-se na resistência.

Sendo assim, este artigo aponta para a relação entre as crianças pequenas da educação infantil, a brincadeira e a arquitetura; esta última, na perspectiva da arte de organizar espaços e criar ambientes para abrigar os diversos tipos de atividades humanas que propõem intencionalidades plásticas.

O que marca os olhares sensíveis sobre as criações de cabanas nos espaços da educação infantil, principalmente aquelas que são produzidas pelas crianças em parceria com a professora. O que pode a cabana ocupar um espaço já traçado dentro de uma sala de referência? Como os espaços externos invadidos pelo processo de criação das crianças 
marcam o currículo? É possível pensar em um currículo aberto com as cabanas? Ou cabanas currículos?

Tais questões delineiam a própria ideia de cabana que traça um percurso, um esconderijo, um espaço de atenção, de cuidado, de aconchego, de produção de imagens realizadas pelas crianças e professoras no cotidiano infantil, que mostram possibilidades de um currículo aberto para a educação infantil em que as crianças pequenas nos levam e demarcam caminhos para o novo.

Deste modo, quando provocamos a olhar para a dimensão daquilo que é prescrito para a educação infantil, conduzimos a leitora e o leitor para outro lugar, para pensar sobre a concepção de infância e crianças que nós adultas/os produzimos e desejamos.

Segundo Silvio Gallo (2018, p. 61),

Colonizar a infância é produzir uma imagem que define o que ela é, o que não é, o que não pode ser. A infância é invenção dos adultos, como já disse Benjamin: as crianças nunca disseram o que é ser criança; se disseram não foram ouvidas; adultos dizem às crianças o que é ser criança.

Sob a condução das crianças e o percurso da criação que este artigo se debruça e, consequentemente nos leva às diferentes cabanas construídas por elas como um movimento de existência. A partir das invenções que as crianças tiveram com as cabanas, os pequenos episódios do cotidiano infantil relatados pela professora, que também é uma das autoras do texto, e das imagens que se conectam como elementos provocativos é que se estrutura este texto.

\section{Espaços que acolhem - As Cabanas Infantis: ato político}

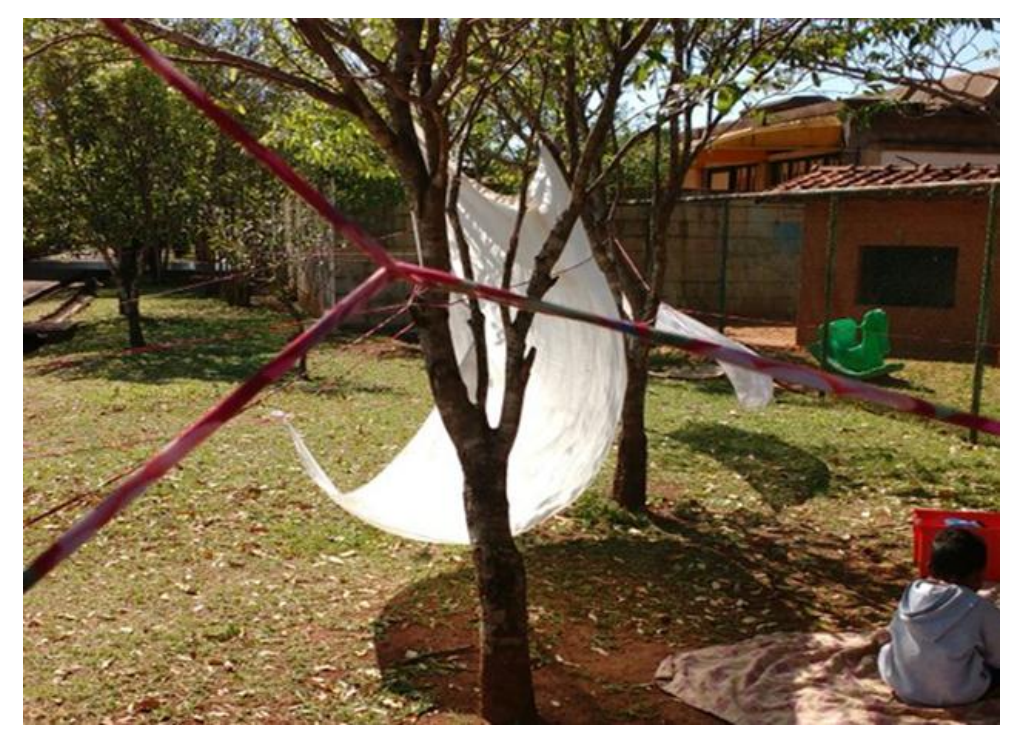

Figura 2: Vento na Cabana.

Fonte: Arquivo da Professora (2017). 
O espaço em que as experiências das cabanas foram realizadas trata-se de uma escola de Educação Infantil Pública, localizada na cidade de Piracicaba, interior de São Paulo, Brasil, com grupo de crianças pequenas entre 4 e 6 anos. Nessa escola da infância valorizam-se proposições pedagógicas, em que o corpo é compreendido em suas múltiplas formas sem a fragmentação do pensar e do fazer, possibilitando experiências sensoriais, perceptivas, imaginativas e criadoras de suas/seus participantes: bebês, crianças e professoras. Esta última, por meio da intencionalidade pedagógica, elabora e organiza essas proposições a partir do conhecimento que possui em relação às crianças com quem trabalha, apoiada em sua experiência docente e com base nos aportes técnicos e teóricos sobre a pedagogia da infância, tendo como princípio do seu trabalho as crianças como sujeitos da interação, do diálogo, da relação com a cultura e a história.

A escola orienta suas ações a partir de dois pressupostos: a Pedagogia da Infância, constituída na interface dos diferentes campos das ciências humanas (Sociologia, História, Psicologia, Filosofia, Antropologia e Geografia) e a Pedagogia Macunaímica, na qual a escola se apresenta com uma pluralidade de características e jeitos de pensar às crianças, acolhendo as múltiplas identidades culturais que remetem a própria cultura brasileira. Faria (1999), utiliza o termo Macunaímica e a descreve como "uma identidade que não é uma; sua especificidade está na indefinição que, por sua vez, reúne muitas definições e muitas especificidades; possibilita aos opostos se encontrarem; 'sem nenhum caráter' é a pluralidade de caracteres diversos" (p. 77).

Com isso, constitui-se como um lugar e espaço da infância que acolhe as diferenças e produz arranjos, a partir de princípios que consideram crianças pequenas e bebês produtores de cultura, atores sociais e de direito, concebendo a educação a partir da intencionalidade pedagógica que integra os mais diferentes modos de experiências, tendo na brincadeira e no cuidar/educar sua centralidade.

Esta concepção que organiza o espaço, o trabalho e a prática docente permite perceber que a participação de cada sujeito que compõe o cotidiano da educação infantil, seja ela o coletivo formado pelas crianças e com as/os adultas/os, autoriza também aprender o desenvolvimento de cada sujeito, que, a priori, é considerado como singular, sendo a partir desta singularidade que o mundo pode ser interpretado de diferentes formas.

O dueto pedagógico assumido pela escola, a Pedagogia da Infância e a Pedagogia Macunaímica, formam um complexo que fundamenta o processo educativo, possibilitando entender as crianças pequenas e os bebês de forma integral, como sujeitos do agora e não do que irão se tornar. E esta visão faz com que a educação infantil se conecte com a ideia de um currículo emergente e aberto, em que o planejamento do cotidiano da creche e da 
pré-escola se configure a partir das relações de intencionalidades pedagógicas que considerem a interferência do que emerge e do que será acolhido, de acordo com as necessidades que afloram e que são decorrentes de um cotidiano em movimento.

O currículo emergente e aberto requer muita dedicação do fazer docente, pois é uma tarefa que exige muito cuidado, escuta e amorosidade, em que envolvem mudanças de paradigmas do que se entende sobre educação para pequena infância, em que há espaço para o pensamento diferente, o que não combina com uma estrutura rígida. Fortunati (2016) nos chama atenção para um olhar atento às relações, "é necessário que adultos sejam capazes de explicitar e refletir sobre as suas intenções, dando peso à sua capacidade de planejar" (p. 12).

Podemos afirmar que tal percepção nos leva a dimensão da multiplicidade do pensar como um contágio que propaga a visibilidade do processo de criação e da produção das culturas infantis. O currículo, neste sentido, se torna aberto para o novo e permite que o conhecimento se configure como elemento propositivo do fazer pedagógico desde a tenra idade.

Eu sou o medo da lucidez. Choveu na palavra onde eu estava.

Eu via a natureza como quem a veste.

Eu me fechava com espumas.

Formigas vesúvias dormiam por baixo de trampas.

Peguei umas ideias com as mãos - como peixes.

(BARROS, Manoel, 2015, s/p.)

\section{Ato ético - Acampamentos e cabanas}

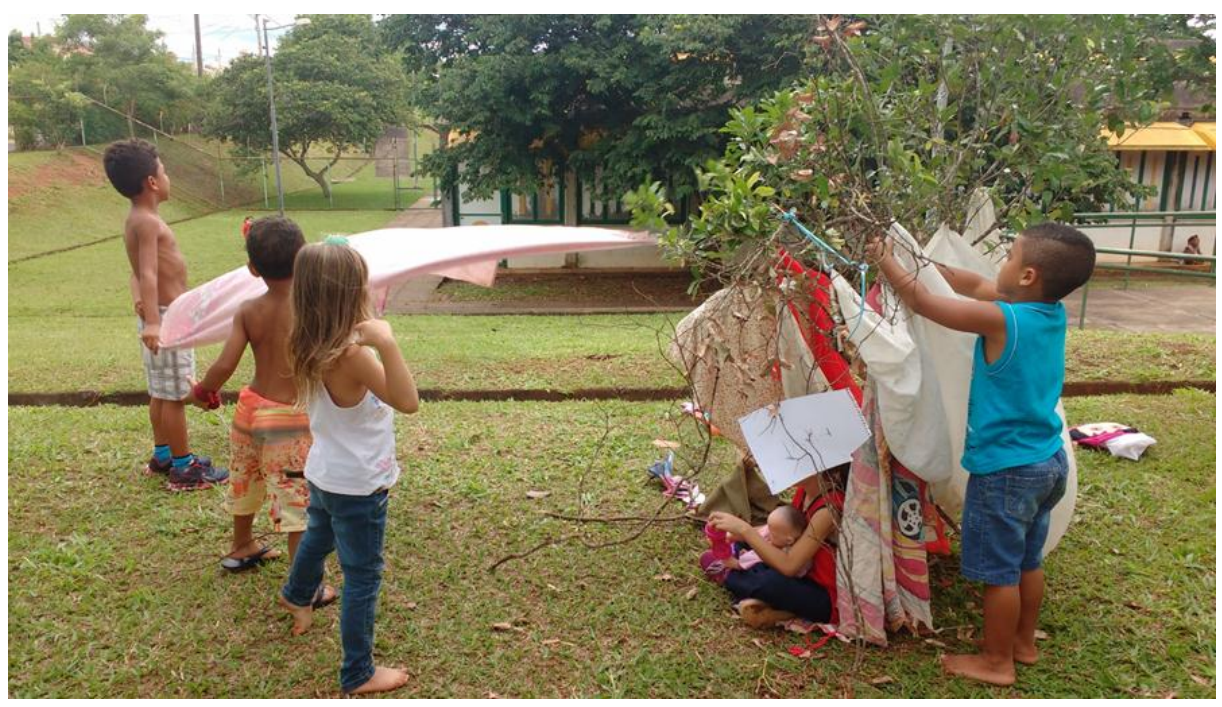

Figura 3: Arranjos.

Fonte: Arquivo da Professora (2017). 
Um dia eu convidei a turma para fazermos cabanas numa área externa à escola, um quintal para além dos muros, e ao convidá-las disse: 'Vamos lá fora fazer um acampamento?' Depois desse dia o espaço só tem este nome. Quando as crianças contavam algo que havia acontecido nesse local, 'sabe lá no acampamento, então...', ou quando queriam ir até lá: 'vamos ao acampamento hoje' (arquivo da professora, 2017).

O vocábulo acampamento vem do sentido de acampar, de instalar provisoriamente ou de alojar temporariamente. Trata-se de um ato efêmero. Entretanto, seu encantamento está na sua montagem, no seu preparo, na criação arquitetônica da cabana. Lençóis, prendedores de roupas, fios, amarrações, papelão, galhos, folhas, pequenas madeiras, árvores, alambrado são suportes dessa construção bela e infantil.

A cabana das crianças é uma criação ornamental, e exige estudo, pesquisa e sabedoria. É um amontoado de muitas coisas que integram muitos elementos, sua imagem é uma instalação estética escorada em algo estável, ou em que essa firmeza dure pelo menos o tempo da brincadeira. Não é fácil, pois quando as mãos pequenas conquistam o prender do lençol, o outro lado se solta; a garantia de muitos prendedores de roupas permite, de certa forma, o encorajamento para continuar a verticalização dessa cobertura.

Aos poucos, quando os materiais vão se transformando em armação/estrutura, as/os pequenas/os se encantam com suas próprias produções, e esta é a questão, em que o criar e o desenvolvimento da técnica se fundem como fundamento de todas as artes. 0 fazer da/na/com a experiência permite que as crianças construam a confiança em si mesmas, em seus corpos e na sua imaginação, e essas referências são fundamentais para compreenderem-se como agentes de seu processo.

Essa arquitetura subjetiva das crianças pequenas que pertence à lógica do sentir e do sentido tem sua raiz na brincadeira infantil, e como aponta Benjamin (2009), criando uma relação nova e incoerente. Nova porque está produzindo seu próprio mundo de coisas, e incoerente pois os absurdos tem espaço privilegiado.

Frente às cabanas erguidas pelo grupo de crianças vislumbramos imagens impregnadas de efeitos e sobreposições. Tais imagens nos remetem a pensar no ilustrador, arquiteto e designer gráfico italiano Federico Babina ${ }^{1}$, que cria edifícios imaginários inspirados em artistas como Miró, e entende que as imagens produzidas pela arquitetura de um prédio, de uma casa, de um edifício são ilustrações, pinturas, desenhos, esculturas, e por isso, obras de artes. De acordo com o artista, ele redescobre o mundo com olhos de criança, e ao alargarmos essa ideia de Babina para as lógicas das cabanas infantis, diante de uma forma de produção bastante peculiar, atentamos para uma qualidade da

\footnotetext{
${ }^{1}$ Conhecer mais sobre o artista em: https://federicobabina.com/
} 
experiência estética infantil, a qual se constitui por meio da beleza arquitetônica do brincar, do experimentar, do fazer, do criar e do inventar. O artista se utiliza do termo "Arquista" para expressar como a arquitetura está impregnada de arte.

Por serem as cabanas repletas de outras lógicas no tempo/espaço, os artefatos que as formam produzem funções de acordo com os momentos propícios às invenções das crianças, e a montagem por meio dos objetos sobrepostos ganham dimensões fantásticas, pois vão aparecendo e compondo tais dimensões. Ou seja, as coisas vão se revelando conforme vão sendo feitas. Ferreira Gullar (2016) nos ensina dizendo que isto é arbitrário, que se trata do acaso, que se cria uma coisa que não existe, na experimentação e exploração dos materiais.

Essas brincadeiras arquitetônicas vivenciadas nos espaços da educação infantil constituem-se como experiências estéticas fundamentais para a produção de conhecimento, para o desenvolvimento infantil, e de acordo com [AUTOR/A] (2017), o contato das crianças pequenas com objetos e suportes significa a possibilidade que elas têm de conhecer através dos sentidos sua concretude e aspecto. Ainda contribuem para que elas ampliem seu conhecimento de mundo e descubram a diversidade dos materiais e das características.

Sobre a questão de objetos como suporte da criação infantil, pensamos a partir das contribuições da arte contemporânea que se apresentam livre em sua constituição, coexistindo sobre/no qualquer objeto como possibilidade de espaço de expressão artística. Isso fez com que o nosso olhar aprendesse a ver de forma alternativa a partir do que é dado, e que as novas combinações entre objetos que aparentemente parecem tão opostos, diante da 'mistura', alcançam boniteza e encantamento.

No caso deste artigo, estamos trabalhando com diferentes maneiras de pensar acerca de suportes, como: objetos, espaços, imaginação, desejos, fantasias. São suportes para criação e invenção infantil que arquitetam brincadeiras potentes e ricas em detalhes, e minuciosidades que, de certa forma, nos impele a querer compreender essa linguagem tão peculiar produzida pelas crianças pequenas. Com isso, nos tornamos apreciadoras/es das produções das crianças e fruidores/as das suas obras em que somos atravessadas/os, pela experiência de apreciar os despropósitos das/os pequenas/os.

Quando pensamos na perspectiva do espaço físico como suporte, Delgado e Muller (2006) colaboram ao mencionar que o espaço não é entendido apenas como um local de passagem, mas de interação, comunicação e de encontro entre os sujeitos, e destes com o meio em que estão inseridos. Com isso, entendemos a educação infantil como um lugar privilegiado dos fazeres de bebês e das crianças pequenas, pois trata-se de um espaço físico e conceitual que compreende a responsabilidade da formação de sujeitos. Sendo 
assim, as crianças pequenas podem e devem ocupar diferentes lugares, inclusive aqueles para além dos muros, pois cada espaço oferece uma diversidade de elementos que são constituídos por materiais e apetrechos que possuem características, formas e design espontâneos, que possibilitam manifestar nas crianças diferentes aparências provocativas do ambiente.

Bruno Munari, em seu livro "Da Cosa Nasce Cosa" (1981), nos permite compreender essa dimensão sensorial da aparência do material, aspecto este próprio do design, o qual não se descuida da importância dos cincos sentidos, tanto na dimensão plural da comunicação quanto do ilegível, a partir do ponto de vista pela licença poética da arte.

Entendemos que as cabanas das crianças são constituídas por esses aspectos propostos por Munari (1981), plural e ilegível, e também pela potência das formas do mundo que são apropriados pelas crianças. Ou seja, o mundo e seus contornos inspiram as/os pequenas/os, e no trilhar deste caminho a produção de sentidos atribuídos acontecem durante a elaboração da brincadeira de arquitetar cabanas, pois cada elemento que compõe a cobertura é um detalhe importante que enriquece as experiências vividas.

As cabanas apreciadas por nosso estudo são tomadas de fantasias e imaginações: esconderijo, moradia, ateliê, dormitório, aconchego. Tais peculiaridades que possuem uma relação prática com as coisas no sentido de fazer, são acontecimentos do cotidiano infantil recheados de muitas surpresas e novidades, engendradas no momento do brincar. Contam uma história, criam histórias e levam para outros lugares, permitem olhar para o processo de criação, criam narrativas, etc.

\section{Efeitos estéticos - Arquitetura da luz}

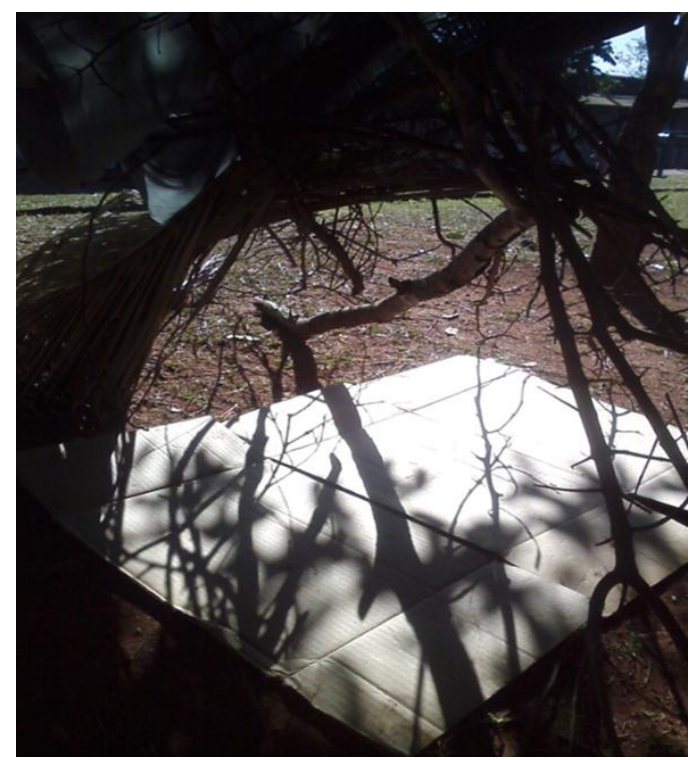

Figura 4: Luz e Sombra.

Fonte: Arquivo da Professora (2017). 


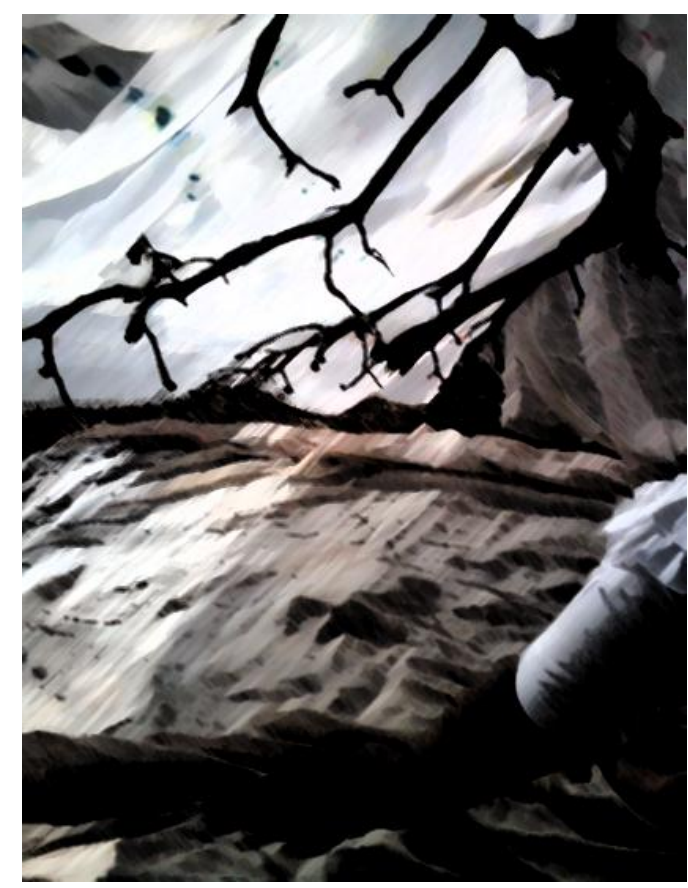

Figura 5: Luz e Sombra.

Fonte: Arquivo da Professora (2017).

Chove torto no vão das árvores.

Chove nos pássaros e nas pedras.

O rio ficou de pé e me olha pelos vidros.

Alcanço com as mãos o cheiro dos telhados.

Crianças fugindo das águas.

Se esconderam na casa. (BARROS, Manoel, 2015, s/p.)

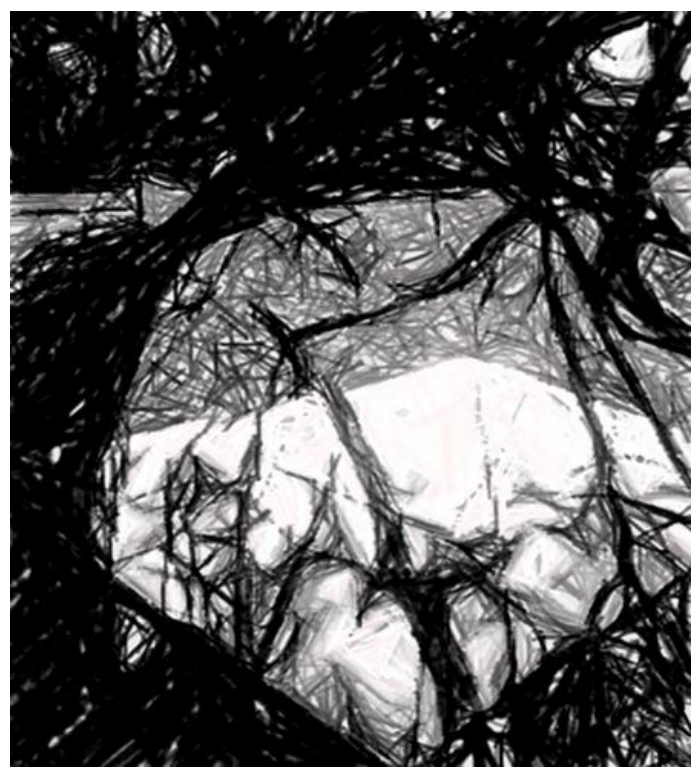

Figura 6: Desenho das Sombras.

Fonte: Arquivo da Professora (2017). 
Esse grupo adora uma cabana. Como havia pouco tecido, porém muitos projetos de cabanas, um grupo de meninos viu no canto do alambrado um amontoado de galhos e folhagens. Sem demora, foram construindo sua cabana escorada na árvore de pendurar (chama-se assim, porque nem todas as árvores que estão no acampamento dão pé para as crianças subirem). Aos poucos e com muita dificuldade foi surgindo a cabana, e quando pronta a o papelão de escorregar no barranco virou o forro para o chão. Os pequenos me chamaram para ver, ficou linda, foi quando um deles me chamou para ver dentro indicando o efeito da sombra dos galhos, era uma imagem encantadora. (Registro escrito da professora, 2017).

Por meio da experiência, somos surpreendidas/os por suas consequências e efeitos. A dimensão estética dos espaços narra uma história, apontam concepções e ideologias sobre as crianças e a pequena infância, o que demarca os efeitos poéticos e as qualidades estéticas que as lógicas infantis produzem.

Sobre o espaço ocupado e a possibilidades que o espaço aberto possibilita na perspectiva de ambiente, Delgado e Müller (2006, p. 8) demonstram que se deve garantir "relações humanas baseadas em sentimentos de respeito pela diversidade, pelas pluralidades das infâncias ali contidas", por isto que as crianças não estão simplesmente a mercê do estímulo visual que o lugar propicia, e sim constituindo-se agentes das suas vivências e experiências.

Por meio da experiência de construir cabanas com materiais da natureza, percebemos possibilidades de experiências estéticas ricas que os tipos e características que esses materiais podem oferecer são diversos e pujantes. Em aspectos abrangentes dessa atividade, esta produção inicia na coleta dos objetos do meio: galhos, folhagens secas, gravetos, troncos que muitas vezes são arrastados em grupos de crianças, e compreendemos os objetos naturais na relação com elas que são propulsoras da inventividade e desenham uma lógica peculiar da infância.

Os encontros fortuitos das crianças com os materiais da natureza propiciaram a experiência de produzir uma cabana com muitos efeitos, seja pela forma arquitetônica ou como podemos observar nas figuras 5 e 6 , pelos efeitos estéticos que surgem da combinação entre iluminação, sombra e imagem ganhando status sensorial.

A relação entre luz, sombra e imagem a partir da perspectiva da Estética da Sombra², a qual inspira o Expressionismo europeu dos anos 20 no cinema Alemão sobre a forma de lidar com as sombras de forma criativa, da iluminação natural e além dela, nos

\footnotetext{
2 Ver em A Obra de arte na era da reprodutibilidade técnica. Walter Benjamin. Zourk, 2014; Catálogo Mostra de Cinema Sombras que Assombram - O Expressionismo no Cinema Alemão. SESC São Paulo, 2014.
} 
permite identificar e compreender a beleza dessa criação infantil e perceber o encanto das silhuetas e o contorno das sombras, tornando o ausente em presente.

É um refinamento de nossa escuta que permite-nos perceber os contrastes e as combinações provocadas pela iluminação como fenômeno da tatibilidade, assim como é apresentado por Benjamin em seu texto sobre "A reprodutibilidade técnica da arte" (1936, 2014), em que os nossos sentidos não estão separados entre si nem na mente, mas é tátil de uma superfície corporal que recepciona sensações estéticas. Frente às imagens das sombras projetadas, a brincadeira de cabana se torna encantadora na perspectiva de quem usufrui dela, neste caso as crianças pequenas - e de quem a aprecia, pois vivencia a experiência do deslumbre de uma obra de arte.

As crianças também ficam fascinadas com a estética da sombra, chamando a professora para se deleitar nessa experiência. Para elas, este mundo mágico de luz, de sombras, de efeitos do sol, da natureza é visto como uma arquitetura da luz que incide nos suportes e pode provocar/causar a sensação de espaço brincante, de luz e espaço inseparáveis. Tendo em vista que a luz invade e define os contornos, tornando visíveis e perceptíveis os espaços e os objetos com os quais as crianças entram em contato, tornase marcante a presença e as relações. "O mundo não foi feito em alfabeto. Senão que primeiro em água e luz. Depois árvore" (BARROS, 2000, s.p).

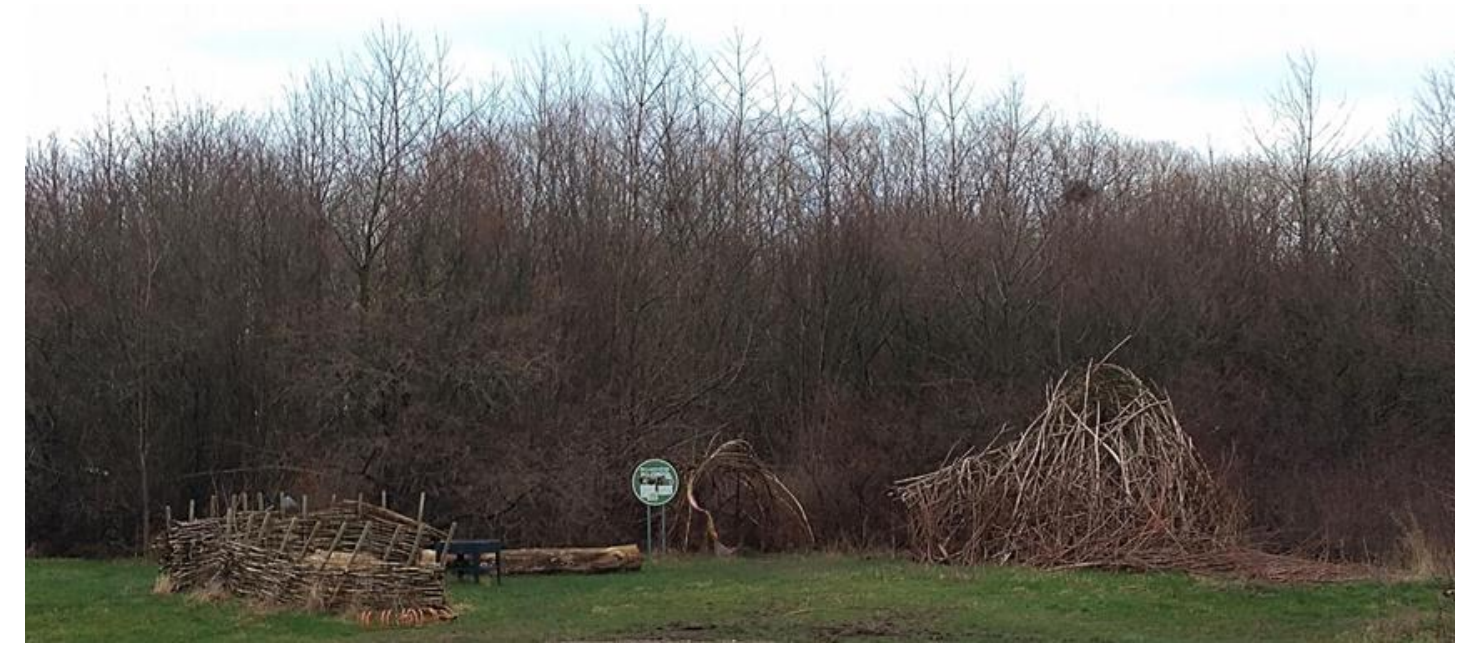

Figura 7: Outras arquiteturas, mas iguais. Fonte: Arquivo da autora (2017).

Neste plano da coexistência de outras arquiteturas que criam movimentos assimétricos e se fundem em processos, a infância vivida em diferentes espaços e que encontramos em narrativas próximas e distantes da memória de um/a andarilho/a que quer contar sobre crianças, lugares, gostos, cheiros, sabores, coisas que também remetem a infância. Deleuze e Guattari (2012) sinalizam uma memória molecular, para além das 
fronteiras, de lógicas distintas, contudo parecidas, a imagem desta obra, de uma cabana instalada na entrada de um bosque, em Lund, na Suécia, marca possibilidades de ocupação de crianças, famílias e comunidade, criando fissuras para se pensar em diferentes lugares.

O encontro das crianças nas fronteiras dos espaços, estão em redes que marcam e criam igualdades e diferenças. As crianças estão em todas as partes, atravessando, arrastando com suas criações a produção das culturas infantis, uma vez que as múltiplas infâncias estão presentes nas espacialidades e territorialidades, produzindo fissuras e desenhando outro tempo.

\section{Instalações e Sobreposições - Breves considerações}

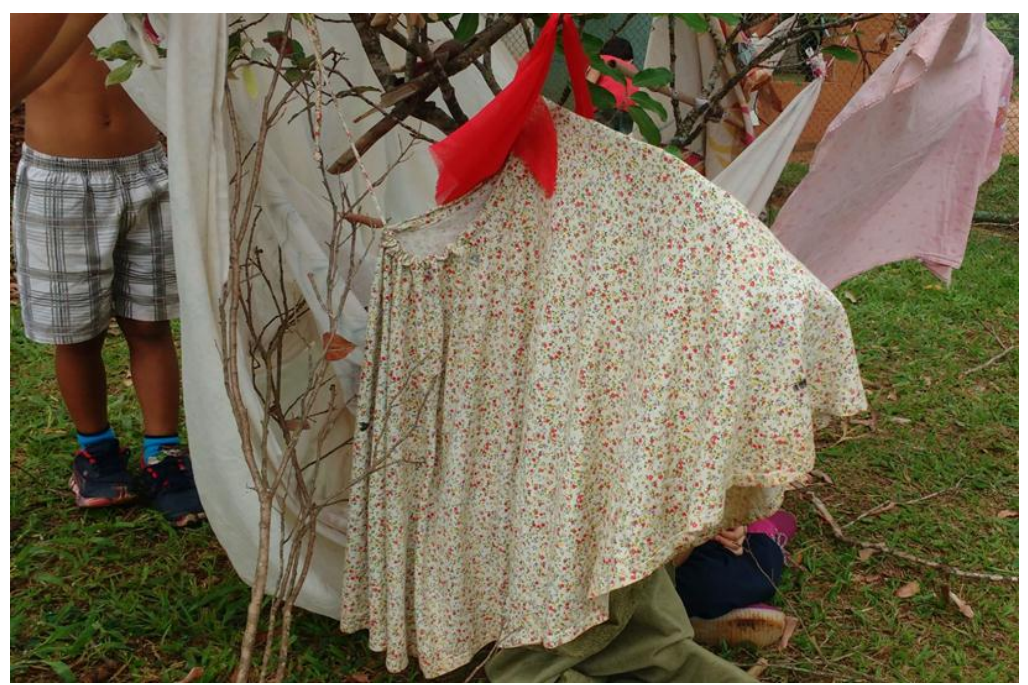

Figura 8: Instalação.

Fonte: Arquivo da Professora (2017).

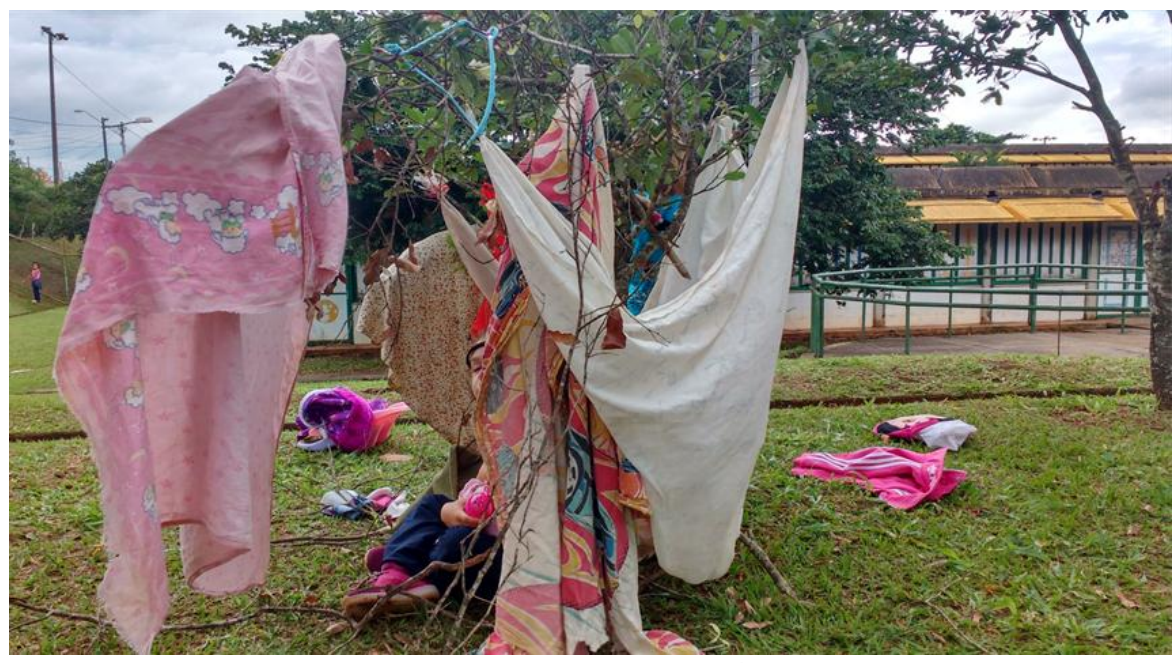

Figura 9: Instalação.

Fonte: Arquivo da Professora (2017).

$\mathrm{Na}$ instalação artística, os objetos são dispostos no espaço, ressignificando lugares e proporcionando experiências sensoriais ao público. Diante das cabanas nos espaços da 
educação infantil, percebemos um cenário muito parecido com as instalações artísticas, suas sobreposições e composições.

A cabana como instalação nos espaços e tempos da educação infantil se lança como propositura de outro olhar para o processo de criação entre crianças e adultos, de pensares sobre a relação entre os objetos, materialidades, as sensações, os sentidos, o planejar para e com as crianças, demarcando possibilidades de um currículo cabanas na educação infantil. Essa arquitetura do brincar que permeia nessa entidade aparentemente imaterial define-se como um jogo repleto de significados, de sensações e de mensagens.

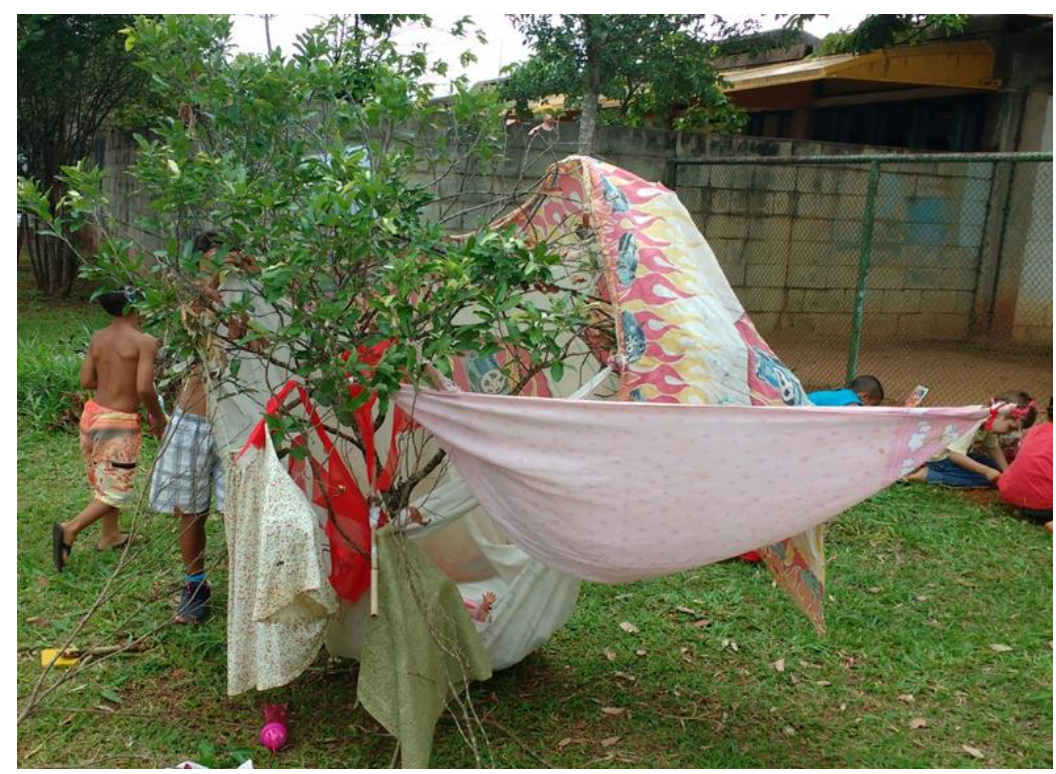

Figura 10: Instalação.

Fonte: Arquivo da Professora (2017).

Aprendemos com as cabanas infantis a potência do pensar/fazer das crianças pequenas que criam a partir da experimentação e exploração de objetos do cotidiano e da natureza. Entendemos que através de um cotidiano da educação infantil rico em intenções, emergente de ideias e aberto às mudanças é possível descobrir e construir novas coisas e inaugurar existências.

Compreendemos, ainda, que os espaços, em uma perspectiva de ambiente são fundamentais para o desenvolvimento das/os pequenas/pequenos que se encantam com as próprias produções. Também entendemos acerca dos aspectos sensoriais dos materiais e dos objetos, bem como da subjetividade infantil que a cabana pode proporcionar, como aconchego, esconderijos, e o deleite de viver fantasias e brincadeiras maravilhosas, tendo em vista que as culturas infantis desenham este modo de pensar e de transformar o currículo da educação infantil. 


\section{Referências}

BARROS, M.; LAFER, A. Arquitetura do silêncio. 1 ed. - Rio de Janeiro: Edições de Janeiro, 2015.

BARROS, M.; LAFER, A. O livro das ignorâncias. Rio de Janeiro: Editora Record, 2000.

BENJAMIN, W. A obra de arte na época de sua reprodutibilidade técnica. Porto Alegre: Zourk, 2014.

BENJAMIN, W. Reflexões: a criança, o brinquedo, a educação. São Paulo: Summus, 2009.

BENJAMIN, W. Obras escolhidas. v. I: Magia e técnica: arte e política. São Paulo: Brasiliense, 1985.

DELEUZE, G; GUATTARI, F. Mil Platôs: capitalismo e esquizofrenia 2, vol. 4. São Paulo: Editora 34, 2012.

DELGADO, A. C. C.; MULLER, F. Apresentação: Tempos e Espaços das Infâncias. Currículo sem Fronteiras, v.6, n.1, p. 5-14, Jan/Jun, 2006.

FARIA, A. L. G. A contribuição dos parques infantis de Mário de Andrade para a construção de uma pedagogia da educação infantil. Educação \& Sociedade, n. 69, 1999.

GALLO, S. "Ir Junto". Os desafios de educar uma infância maior. In: SANTOS, S. E.; SANTIAGO, F; BARREIRO, A; MACEDO, E El de; FARIA, A. L. G. (org.). Pedagogias descolonizadoras e infâncias: por uma educação emancipatória desde o nascimento. Maceió: EDUFAL, 2018.

MUNARI, B. Das Coisas Nascem Coisas. 2a ed. São Paulo: Martins Fontes, 1981, 388 páginas.

VIANA, Z.; GASTAL, G. A Arte Existe Porque a Vida Não Basta. Produção Mapa Filmes: Brasil, 2016.

\footnotetext{
' Doutoranda e Mestra em Educação pela UNIMEP, pedagoga e professora de EMEI de Piracicaba, militante do FEIPIRA, membra do HINAS Linhas Narrativas Pedagógicas, Escritas (auto)biográficas e Memória: Desenvolvimento Profissional Docente e Práticas Educativas.

ii Doutorando em Educação na UNESP/Rio Claro, pedagogo e mestre em Educação pela UNICAMP, diretor de EMEI em Piracicaba-SP, militante do FPEI (Fórum Paulista de Educação Infantil), pesquisador do grupo IM@GO-UNESP e do GEPEDISC linha Culturas Infantis, UNICAMP.
}

Como citar esse artigo:

OLIVEIRA, Fernanda Ferreira; SILVA, Peterson Rigato. Arquiteturas do Brincar: cabanas encantadas. Revista Digital do LAV, Santa Maria: UFSM, v. 14, n. 2, p. 173-186, mai./ago. 2021. 